\title{
Rare case of Amlodipine Induced Hepatitis: A case report
}

\author{
Francis Egbuonu ${ }^{1}$, Bilal Fazal ${ }^{2 *}$, Manal Atwan ${ }^{3}$ and Albert Davies ${ }^{4}$ \\ ${ }^{1}$ Gastroenterology Registrar, Furness General Hospital, Barrow-in-Furness, United Kingdom \\ ${ }^{2}$ Foundation year 2 Doctor, Furness General Hospital, Barrow-in-Furness, United Kingdom \\ ${ }^{3}$ Consultant Histopathologist, Royal Lancaster Infirmary, Lancaster, United Kingdom \\ ${ }^{4}$ Gastroenterology Consultant, Furness General Hospital, Barrow-in-Furness, United Kingdom
}

\begin{abstract}
We herein report an unusual case of chronic drug-induced cholestatic hepatitis secondary to the calcium channel blocker, Amlodipine. The patient presenting, was a 74-year-old Caucasian female referred to the gastroenterology clinic with an incidental finding of deranged liver enzymes. The most significant of which were her gamma-glutamyl transferase (GGT) and alkaline phosphatase (ALP), which were 40 times and 10 times their upper limit of normal respectively. The liver enzymes blood test done 16 months prior to this was normal. A liver biopsy was arranged, which showed peri-portal lymphoid infiltration with prominent eosinophils, focal necrosis in the lobules and extensive bilirubin stasis in the hepatocytes. The conclusion was that the histology was suggestive of chronic drug-induced cholestatic hepatitis. Her only medication was amlodipine $5 \mathrm{mg}$, which she had been on for about 8 months. Subsequent liver function testing after discontinuing Amlodipine demonstrated normalizing liver enzymes. This case is an example of idiosyncratic drug induced liver injury and supports the sparse existing literature which has been reported on amlodipine-induced hepatoxicity.
\end{abstract}

\section{Introduction}

A 74-year-old Caucasian female presented to gastroenterology clinic with deranged liver tests which were incidentally found during pre-operative investigations for repair of a thoracic aortic aneurysm. Her past medical history included the aforementioned thoracic aortic aneurysm, aortic regurgitation, osteoarthritis, hypertension and a previous right inguinal hernia repair. Her only medication was amlodipine $5 \mathrm{mg}$ which she had been on for about 8 months.

She smoked six cigarettes per day and was not a heavy drinker. There was no history of intravenous drug use or previous blood transfusions. She had no relevant family history or travel history. Physical examination was unremarkable. There was no jaundice or stigmata of liver disease.

Her liver enzymes were deranged as shown in table 1 . The serum alkaline phosphatase (ALP) was about 10x the upper limit of normal. The serum alanine aminotransferase (ALT) was $1.5 \mathrm{x}$ the upper limit of normal. The serum gamma glutamyl transferase (GGT) was 40x the upper limit of normal. Her international normalised ratio (INR) was normal. The liver enzymes blood test done 16 months prior to this was normal.

Viral and auto-immune hepatitis screen was negative. Ferritin, alpha-fetoprotein and alpha 1 anti-trypsin screen were all negative. A liver biopsy was arranged.

Liver biopsies generated two fragmented core biopsies of liver measuring $12 \mathrm{~mm}$ and $14 \mathrm{~mm}$ and containing 14 portal tracts (Figure 1). There was no evidence of established fibrosis. There was focal mild to moderate peri-portal lymphoid infiltrate. Eosinophils were prominent within the peri-portal and lobular infiltrate. There was no piecemeal or confluent necrosis but there was focal necrosis in the lobules. No granulomas were identified. The hepatocytes showed extensive bilirubin stasis. The conclusion was that the histology was suggestive of chronic drug-induced cholestatic hepatitis.

\section{Outcome}

She was advised to stop the amlodipine and her LFTs started to gradually improve over the next few months.

\section{Discussion}

Amlodipine belongs to the dihydropyridine group of calcium channel blockers. It is used for its antihypertensive and antianginal effects. It blocks the L-type calcium channels and thus prevents entry of calcium into vascular smooth muscle cells. This causes arterial/ arteriolar dilatation and reduced blood pressure. It also causes coronary artery dilatation and improves myocardial blood flow [1,2].

Amlodipine is not an intrinsic hepatotoxin and this case would be classed as an idiosyncratic drug-induced liver injury. Idiosyncratic drug reactions can be unpredictable, non-reproducible and may have a variable latency period. Conversely intrinsic hepatotoxins (i.e. paracetamol) cause predictable, reproducible, dose-dependent hepatotoxicity with a brief latency period.

Idiosyncratic hepatotoxicity is commonly classified into the metabolic type and immune type. In metabolic idiosyncrasy, there is acquired or genetic variation in drug metabolism. The immune variation describes the development of immune reactions to the drug or its metabolites. These mechanisms may have some overlap [3-5].

${ }^{\star}$ Correspondence to: Bilal Fazal, Foundation year 2 Doctor, Furness General Hospital, Barrow-in-Furness, United Kingdom, Tel: 07731509405; E-mail: bilalmuhammadno.1@gmail.com

Key words: amlodipine, hepatitis, hepatotoxic

Received: September 19, 2019; Accepted: October 18, 2019; Published: October 25,2019 


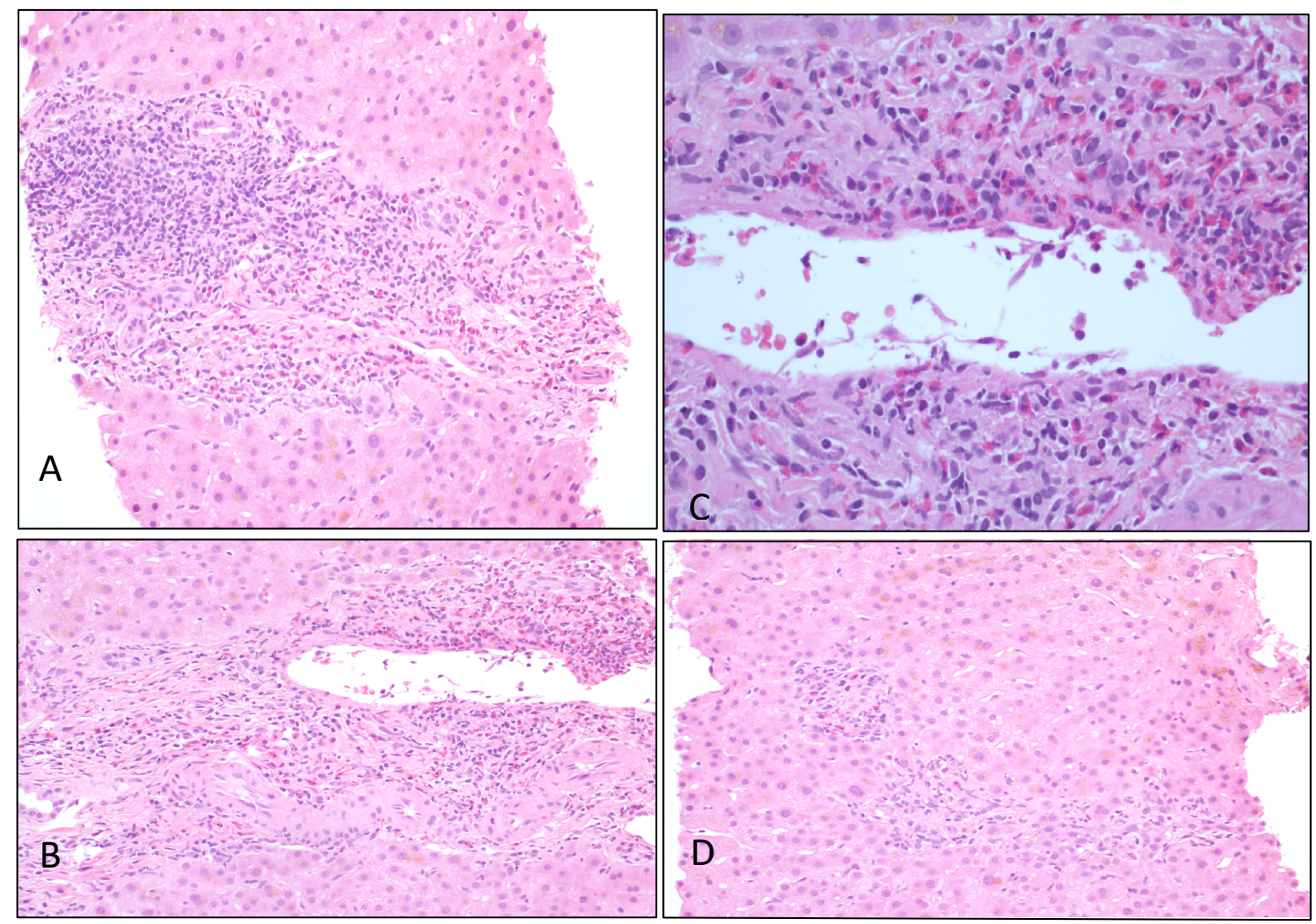

Figure 1. (A) Acute hepatitis with peri-portal lymphoid infiltrate and eosinophils (B) Peri-portal inflammation (C) Prominent eosinophils in peri-portal area (D) Bilirubinostasis and lobar inflammation with prominent eosinophils

Table 1. Timeline of liver enzyme derangement

\begin{tabular}{|c|c|c|c|c|c|c|c|c|c|}
\hline $\begin{array}{c}\text { Test (units \& reference } \\
\text { range) }\end{array}$ & $04 / 02 / 2016$ & 28/06/2017 & 01/08/2017 & 29/08/2017 & $\begin{array}{l}\text { Amlodipine } \\
\text { stopped }\end{array}$ & 27/10/2017 & $07 / 02 / 2018$ & $18 / 05 / 2018$ & $09 / 11 / 2018$ \\
\hline ALT (0-35 IU/L) & 9 & 61 & 84 & 112 & & 53 & 47 & 16 & 13 \\
\hline ALP (30-130 IU/L) & 113 & 1450 & 1417 & 1393 & & 1284 & 1002 & 557 & 364 \\
\hline Bilirubin $(0-21 \mu \mathrm{mol} / \mathrm{L})$ & 6 & 13 & 15 & 16 & & 15 & 12 & 11 & 11 \\
\hline GGT (0-38 IU/L) & 35 & 1558 & 1756 & 1939 & & 1564 & 1313 & 354 & 221 \\
\hline INR & N/A & 0.9 & 1.0 & 1.0 & & 1.0 & N/A & 1.0 & 1.0 \\
\hline
\end{tabular}

Idiosyncratic drug induced liver injury can be difficult to diagnose especially as most patients are on multiple agents. It was less complicated in this case as the patient was on a single medication and withdrawal of that medication was accompanied by improvement in the liver tests. Confirmation of diagnosis could be done with a careful and monitored re-exposure to the agent.

This case demonstrates the potential hepatotoxic effects of amlodipine and supports the sparse existing literature which has been reported on amlodipine-induced hepatoxicity [6-9].

\section{References}

1. Waller D, Renwick A. and Hillier K. (2011) Medical pharmacology and therapeutics. Edinburgh: Saunders Elsevier.

2. Rang H. (n.d.). Rang \& Dale's Pharmacology. Elsevier.

3. Qayed E, Srinivasan, S. and Shahnavaz, N. (2016) Sleisenger and Fordtran's gastrointestinal and liver disease.

4. Lefkowitch J and Scheuer P (2016) Scheuer's liver biopsy interpretation. 9th ed. Edinburg: Elsevier.

5. Kuntz E and Kuntz H (2008) Hepatology. 3rd ed. Heidelberg: Springer.
6. Basile C, Mascia E (1999) Dihydropyridine calcium channel blockers: a rare and reversible cause of hepatotoxicity with cholestasis in a CAPD patient. Nephrol Dial Transplant 14: 2776-2777. [Crossref]

7. Hammerstrom AE (2015) Possible Amlodipine-Induced Hepatotoxicity After Stem Cell Transplant. Ann Pharmacother 49: 135-139. [Crossref]

8. Lafuente NG (2000) Calcium channel blockers and hepatotoxicity. Am J Gastroenterol 95: 2145. [Crossref]

9. Demirci H, Polat Z, Kantarcioglu M, Kekilli M, Uygun A, et al. (2013) Shortterm amlodipine induced liver injury: an extremely rare acute complication. Acta Gastroenterol Belg 76: 441. [Crossref]

Copyright: (C)2019 Egbuonu F. This is an open-access article distributed under the terms of the Creative Commons Attribution License, which permits unrestricted use, distribution, and reproduction in any medium, provided the original author and source are credited. 